\title{
Effects of alteplase in the treatment of acute ischemic stroke
}

\author{
This article was published in the following Dove Press journal: \\ International Journal of General Medicine \\ 5 September 2012 \\ Number of times this article has been viewed
}

\section{Josef Yayan}

Department of Internal Medicine, Vinzentius Hospital, Landau, Germany
Correspondence: Josef Yayan

Department of Internal Medicine, Vinzentius Hospital, Cornichonstraße 4 ,

D-76829 Landau, Germany

Tel +496341176128

Fax +4963 4II42254

Email josef.yayan@hotmail.com
Background: For the last 15 years, alteplase (recombinant tissue plasminogen activator) has been used widely throughout the world for the treatment of acute ischemic stroke. Although considered to be safe and effective, like all drugs, alteplase has side effects.

Methods: This retrospective cohort study was conducted in the intensive care unit of the department of internal medicine in a mid-size peripheral acute hospital in Germany. Patients with acute ischemic stroke who underwent alteplase-induced thrombolysis were investigated.

Results: Among the 1017 patients admitted for stroke investigation, 23 (2.26\%) received thrombolytic therapy consisting of intravenous alteplase. Of these, six patients (26.09\%) experienced complications, ie, four (17.39\%) had intracerebral hemorrhage, one (4.35\%) developed orolingual angioedema, and one (4.35\%) had a hematoma on the right arm. After treatment with alteplase, two $(33.33 \%)$ patients in the study group $(n=6)$ died because of intracerebral hemorrhage and one (16.67\%) died because of aspiration pneumonia. One (5.88\%) patient in the control group $(n=17)$ died of cerebral edema.

Conclusion: The incidence of stroke and number of patients treated with alteplase in the examined hospital subunit has not increased in recent years. Also, in this study, no statistically significant difference was found in the incidence of various complications occurring during treatment for acute ischemic stroke with alteplase, but intracerebral hemorrhage was the most common complication.

Keywords: alteplase, complications, acute ischemic stroke, safety, efficacy

\section{Introduction}

The US Food and Drug Administration approved the intravenous use of recombinant tissue plasminogen activator (rt-PA) alteplase for the treatment of acute ischemic stroke in 1996, and since then, this has been the only drug approved in this indication, and it is recommended as first-line treatment by most stroke associations worldwide. ${ }^{1-6}$ Nonetheless, concerns remain regarding the safety of this drug in routine clinical use. ${ }^{2}$ For various reasons, only a small proportion of patients with ischemic stroke have been treated using alteplase. Therefore, little information is available about its side effects.

It is well known that thrombolysis as treatment for ischemic stroke is associated with an increased risk of symptomatic intracranial hemorrhage. ${ }^{2}$ However, it is difficult to compare the incidence of this complication between studies, because different definitions of intracranial hemorrhage have been adopted by different investigators. In the present study, symptomatic intracranial hemorrhage is defined as a typical homogeneous, hyperdense lesion with a sharp border with or without edema or mass effect within the brain. ${ }^{2}$ 
The aim of this retrospective study was to report our experience with rt-PA treatment for stroke patients in a subunit of the department of internal medicine of a medium-sized hospital responsible for treating such patients. For this purpose, recent trends in the use of alteplase in a peripheral hospital with a small stroke unit were examined. The incidence of complications due to treatment with alteplase was determined and compared with that reported previously. Because of the broad scope of this study, its results, combined with those of previous studies, may offer novel insights into the effects of treatment with alteplase.

\section{Materials and methods}

\section{Study groups and patient data}

This was a retrospective cohort study of patients with acute ischemic stroke who underwent thrombolysis with alteplase between 2007 and 2011. It was conducted in a small stroke subunit at the department of internal medicine in Vinzentius Hospital, a medium-sized 400-bed acute general hospital in Landau, Germany. The study group included all patients with acute ischemic stroke who were thrombolysed with intravenous alteplase and experienced complications due to this treatment. Results in this group of patients were compared with those from a control group, comprising patients with acute ischemic stroke who received the same treatment but experienced no complications. Head scanning using computed tomography or magnetic resonance imaging was conducted for all patients. Those with contraindications before thrombolysis were excluded. In all cases, intravenous alteplase $(0.9 \mathrm{mg} / \mathrm{kg})$ was administered within the recommended time frame, ie, 3 hours from the onset of neurological symptoms. The patients remained under around-the-clock supervision by highly trained nurses. The doctor in charge assessed stroke severity using the National Institutes of Health Stroke Survey (NIHSS) score. For all stroke patients, the modified Rankin Scale score and the Barthel activities of daily living index were also determined by well trained nurses before the event, 24 hours thereafter, and before discharge. All patient data, including demographics, medical history, recorded onset time of stroke symptoms, last known symptom-free time point, time of arrival at the hospital, inhospital diagnostic results, treatments and procedures, rehabilitation, discharge treatments and counseling, rt-PA treatment initiation time, complications, inhospital mortality, and discharge destination, were recorded by trained hospital personnel. Heart rate, blood pressure, electrocardiography results, blood glucose levels, hematocrit, blood clotting, kidney functions, and blood lipid levels, were also included in the patient records, if available. The anatomical location of the acute ischemic insult was classified according to the Oxford Community Stroke Project classification. Using all these parameters, clinical symptoms were compared between the test and control groups. Further, the use of aspirin before the event and secondary prevention medication against a recurrent stroke was evaluated. The cardiovascular risk factors examined included elevated blood pressure, diabetes mellitus, hypercholesterolemia, hypertriglyceridemia, obesity, and smoking. Comorbidities and the length of the hospital stay were also compared between the groups. A major adverse cardiac event was defined as death, a previous history of stroke, or myocardial infarction.

\section{Statistical analysis}

The odds ratio (OR) was calculated for the complications on treatment with alteplase, ie, cerebral hemorrhage, orolingual angioedema, or hematoma on the right arm. The Chi-square test was used to compare paired parameters among gender distribution in neurological symptoms, heart rhythm, cardiovascular risk factors; physical, speech, mobilization, antiplatelet and anticoagulant medical treatment therapy; persistence and duration of symptoms until 60 minutes and longer than 24 hours; rehabilitation; and comorbidities in both groups. The confidence interval (CI) of a proportion was calculated for the number of patients with intracerebral hemorrhage after treatment through alteplase for acute ischemic stroke. A one-sample $t$-test with 4 degrees of freedom against the mean was used to compare the therapeutic trends and number of times thrombolytic therapy was administered to patients hospitalized for stroke investigation between the test and control groups. Friedman's test was used to compare the complication rate with alteplase treatment. The MannWhitney $U$ test was used to compare the total number of neurological symptoms diagnosed, vital and laboratory parameters, NIHSS score, onset time, number of cardiovascular risk factors diagnosed, length of hospital stay, and total number of comorbidities diagnosed. The survival rate for both groups was calculated using the Kaplan-Meier method. Data normality was assessed using the Kolmogorov-Smirnov test. $P<0.05$ was considered to be statistically significant. Results involving the mean and standard deviation (SD) are shown as such.

\section{Results}

In total, 1017 patients were admitted for stroke evaluation to Vinzentius Hospital between 2007 and 2011. Remarkably, in this 5-year period, $23(2.26 \%, 95 \%$ CI 1.35-3.17) patients 
( $n=1017)$ with acute ischemic stroke underwent thrombolysis with intravenous alteplase $(5 \pm 3$ patients per year on average, $P=0.79)$. The mean number of patients hospitalized for stroke investigation per year was $203 \pm 63$, and no increase in this trend $(P=0.99)$ according to a one-sample $t$-test was found in these years (Figure 1). A significant difference was found $(P<0.01)$ in the number of thrombolysis treatments compared with the number of patients hospitalized for stroke investigation (Figure 1).

The mean age of the study and control groups was $76.83 \pm 8.998$ and $66.82 \pm 10.71$ years, respectively. The Chi-square test showed no significant difference in the number of men and women who received intravenous thrombolytic treatment with alteplase $(P=0.56)$. This treatment was administered to four $(66.67 \%)$ men in the study group $(n=6)$ and nine $(52.94 \%)$ in the control group $(n=17)$, but to two women $(33.33 \%)$ in the study group and eight women $(47.06 \%)$ in the control group.

Figure 2 shows the complications due to alteplase treatment. Friedman's test showed no statistically significant difference $(P=0.47)$ in the incidence of various complications, although intracerebral hemorrhage was the most common complication, observed in four $(17.39 \%, 95 \% \mathrm{CI}$ 1.9-32.88) patients $(n=23)$. Two patients had massive intracerebral bleeding, and two had minor secondary intracranial hemorrhage of $10 \mathrm{~mm}$ and $7 \mathrm{~mm}$ midline shift on cranial computed tomography. The OR compared with the control group was less for both cerebral hemorrhage (OR 0.0514,
95\% CI $0.0021-1.2722, P=0.07)$, as well as orolingual angioedema and hematoma on the right arm (OR 0.078, 95\% CI 0.0003-0.2201, $P=0.004$ ).

All patients underwent cranial computed tomography. Head magnetic resonance imaging was performed for three patients $(50 \%)$ in the study group and 12 patients $(70.59 \%)$ in the control group $(P=0.36)$. A significant difference was found in the number of neurological symptoms diagnosed $(P=0.01)$, and partial anterior circulation infarct was the most common radiological diagnosis on computed tomography or magnetic resonance imaging (Table 1). The cause of acute cerebral ischemia was cardioembolism in four patients $(66.67 \%)$ in the study group and five patients $(29.41 \%)$ in the control group, and it was internal carotid artery stenosis in two patients $(11.76 \%)$ in the control group. Further, the two groups differed statistically in terms of the presence of diabetes as a cardiovascular risk factor $(P=0.02$, Table 2$)$.

No statistically significant difference was found in vital and laboratory parameters between these groups (Table 3 ). Similarly, no statistically significant difference was found in the antiplatelet anticoagulation medical treatments (Table 4). Table 5 shows the results of the NIHSS score, Rankin Scale, and Barthel index; a statistically significant difference was found in Rankin Scale before discharge $(P=0.04)$ between the groups. Further, no statistical difference was found in rehabilitation, treatment on discharge, counseling (Table 6), time of onset of stroke symptoms,

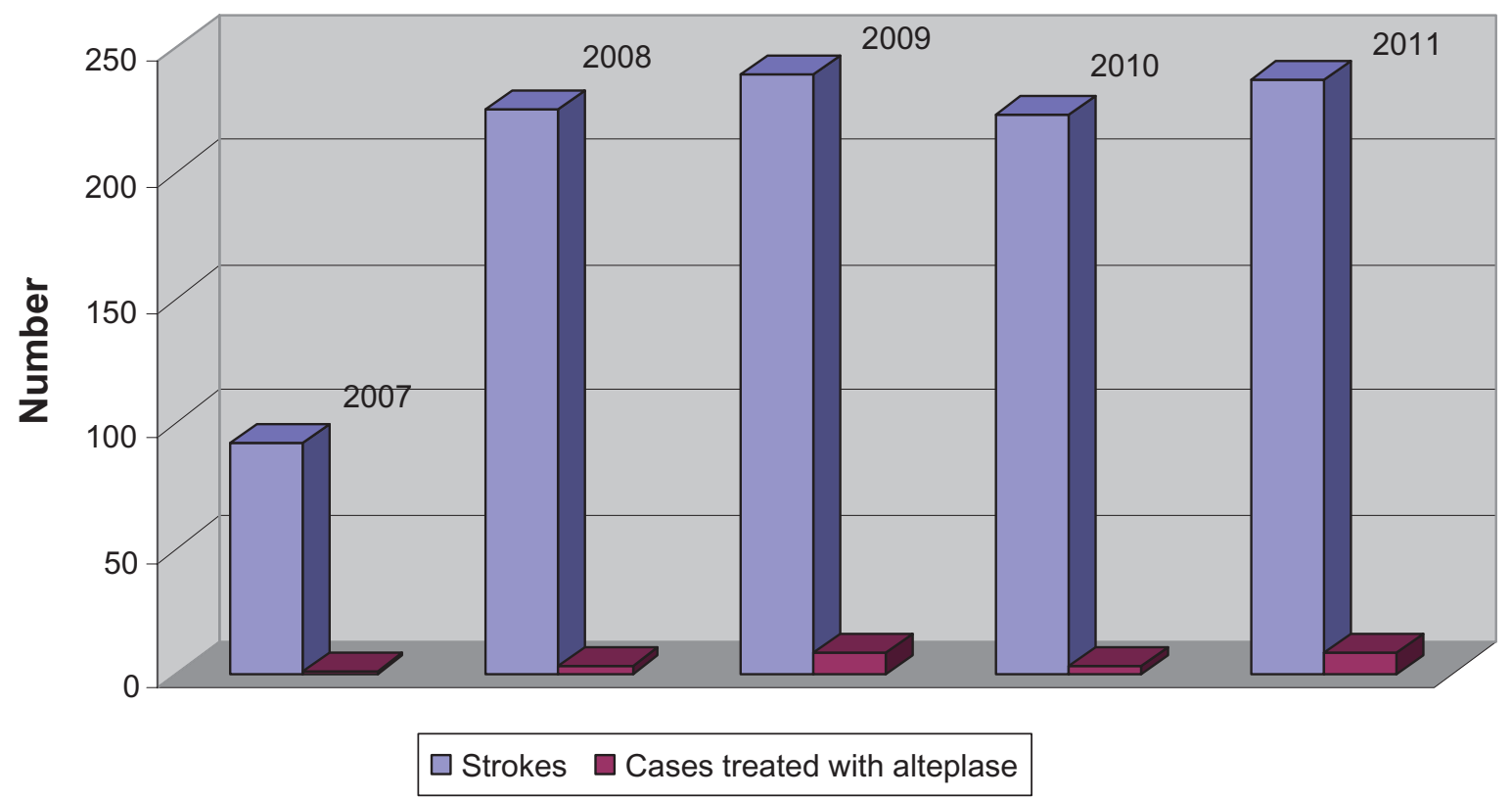

Figure I Number of strokes and cases in which thrombolysis treatment with alteplase was administered between 2007 and 20 I I. 


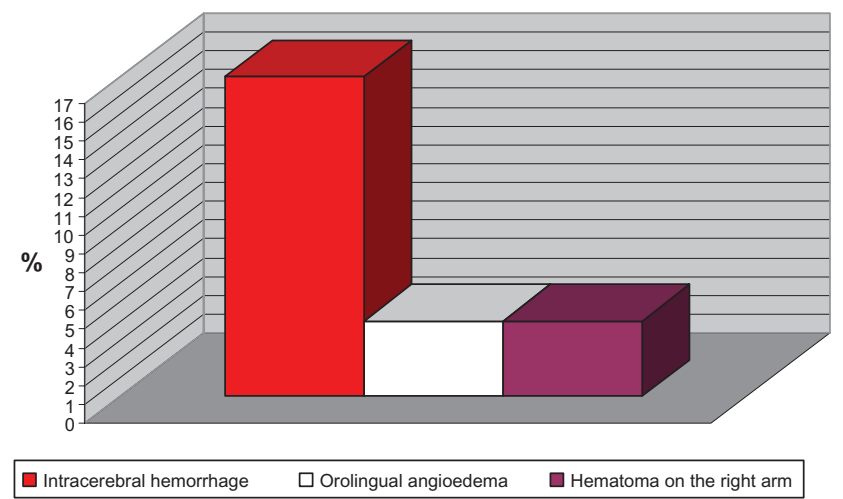

Figure 2 Complications due to alteplase treatment.

and time lines (Table 7), or in comorbidities between the groups (Table 8 ). The average length of hospital stay was $17.67 \pm 13.74$ days in the study group and $8.29 \pm 4.33$ days in the control group. According to the Kolmogorov-Smirnov test, the length of hospital stay showed a normal distribution of 1.88 and 2.53 in the study and control groups, respectively, with a significant deviation of at least $99 \%$ from the normal distribution. The groups did not differ significantly in terms of length of hospital stay $(P=0.26)$.

In terms of major adverse cardiac events, one (16.67\%) patient in the study group and three $(17.65 \%)$ in the control group had a history of stroke $(P=0.96)$. Among the six patients in the study group, two patients (33.33\%) died; thus, the probability of survival determined using the Kaplan-Meier method was 66.66\% (95\% CI 20.47-112.86). In the control group as well, two of 17 patients $(11.76 \%)$ died. Therefore, the probability of survival was $88.24 \%$ (95\% CI 71.93-104.54). The probability of survival was not significantly different between the groups in this study $(P=0.23)$.

\section{Discussion}

The number of patients admitted to this hospital for stroke investigation remained mostly the same year by year, showing little variation over the 5 years of the test period. Thrombotic therapy with alteplase was administered to about five patients every year at this hospital. Although the efficacy of rt-PA for acute ischemic stroke has been demonstrated, less than $5 \%$ of qualifying patients actually receive rt-PA. ${ }^{2}$

Epidemiological studies, mainly based on surveys conducted in western Europe, have shown that stroke is more common in men than in women, and that women become more severely ill after suffering a stroke. ${ }^{7}$ The mismatch between the genders is much greater than that described previously. ${ }^{7}$ In the present study as well, more men than

Table I Neurological symptoms

\begin{tabular}{|c|c|c|c|c|}
\hline Neurological symptoms & $\begin{array}{l}\text { Study group diagnoses } \\
(\mathrm{n}=12)\end{array}$ & $\begin{array}{l}\text { Control group diagnoses } \\
(n=36)\end{array}$ & $\begin{array}{l}\% \text { Study/control } \\
\text { group }\end{array}$ & $P$ value \\
\hline \multicolumn{5}{|l|}{ Right hemiparesis } \\
\hline Male & 4 & 5 & $33.33 / 13.89$ & \\
\hline Female & I & 3 & $8.33 / 8.33$ & 0.51 \\
\hline \multicolumn{5}{|l|}{ Left hemiparesis } \\
\hline Male & 0 & 3 & $0.00 / 8.33$ & \\
\hline Female & 1 & 4 & $8.33 / 11.11$ & 0.41 \\
\hline \multicolumn{5}{|l|}{ Right-sided facial paralysis } \\
\hline Male & I & I & $8.33 / 2.78$ & \\
\hline Female & 0 & 2 & $0.00 / 5.56$ & 0.25 \\
\hline \multicolumn{5}{|l|}{ Left-sided facial paralysis } \\
\hline Male & 0 & I & $0.00 / 2.78$ & \\
\hline Female & 0 & I & $0.00 / 2.78$ & $>0.99$ \\
\hline \multicolumn{5}{|l|}{ Dysphasia } \\
\hline Male & 2 & 6 & $16.67 / 16.67$ & \\
\hline Female & I & 7 & $8.33 / 19.44$ & 0.52 \\
\hline \multicolumn{5}{|l|}{ Dysphagia } \\
\hline Male & 2 & 2 & $16.67 / 5.56$ & \\
\hline Female & 0 & 1 & $0.00 / 2.78$ & 0.36 \\
\hline $\begin{array}{l}\text { Total number of diagnoses } \\
(\mathrm{n}=48)\end{array}$ & 12 & 36 & $100 / 100$ & $<0.01$ \\
\hline \multicolumn{5}{|l|}{$\mathrm{PACl}$} \\
\hline Male & 2 & 6 & $40 / 46.15$ & \\
\hline Female & 3 & 7 & $60 / 53.85$ & 0.81 \\
\hline
\end{tabular}

Abbreviation: $\mathrm{PACl}$, partial anterior circulation infarct. 
Table 2 Cardiovascular risk factors

\begin{tabular}{lllll}
\hline $\begin{array}{l}\text { Cardiovascular } \\
\text { risk factors }\end{array}$ & $\begin{array}{l}\text { Study } \\
\text { group } \\
(\mathbf{n = 6 )}\end{array}$ & $\begin{array}{l}\text { Control } \\
\text { group } \\
(\mathbf{n}=\mathbf{~ 1 7 )}\end{array}$ & $\begin{array}{l}\text { \% } \\
\text { Study/control } \\
\text { group }\end{array}$ & P value \\
\hline Hypertension & 4 & 13 & $66.67 / 76.47$ & 0.64 \\
Diabetes & 5 & 5 & $83.33 / 29.4 \mathrm{I}$ & 0.02 \\
Hypercholesterolemia & 2 & $\mathrm{I}$ & $33.33 / 5.88$ & 0.09 \\
Hypertriglyceridemia & 0 & $\mathrm{I}$ & $0.00 / 5.88$ & 0.54 \\
$\begin{array}{l}\text { Obesity } \\
\text { Smoking }\end{array}$ & 2 & 4 & $33.33 / 23.53$ & 0.64 \\
$\begin{array}{l}\text { Total number } \\
\text { of diagnoses }\end{array}$ & 0 & 3 & $0.00 / 17.65$ & 0.27 \\
( $\mathrm{n}=40)$ & 13 & 27 & & 0.39 \\
\hline
\end{tabular}

women were affected by acute ischemic stroke, and the condition of the men was worse than that of the women, even after rt-PA treatment.

Public concern about the high stroke-related morbidity, mortality, and disability levels has been increasing globally. During the last few decades, routine statistics for cerebrovascular disease mortality have presented different rates in Europe and countries peripheral to Europe. ${ }^{8}$ Nonetheless, for both genders, markedly increasing rates have been noted, moving from west to east, with few exceptions. ${ }^{8}$ In most western European countries, stroke mortality has decreased significantly in recent decades. ${ }^{9,10}$ In contrast, the mortality rate was high in the present study.
In general, elderly patients with stroke have worse outcomes compared with their younger counterparts. ${ }^{11}$ Stroke severity, concurrent medical problems, prestroke disability, and less aggressive acute and chronic management are a few factors contributing to this. ${ }^{11}$ Acute thrombolysis is the only proven treatment for acute ischemic stroke. However, elderly patients have mostly been excluded from acute revascularization studies, mostly because of their overall poor prognosis and the risk of hemorrhagic complications from these treatments. ${ }^{11}$ Despite this, there is no evidence to suggest that the risk-benefit ratio of thrombolysis is substantially different in the elderly than in younger ischemic stroke patients. ${ }^{11}$ Therefore, patients who meet the eligibility criteria for thrombolysis should not be denied this therapy on the basis of age alone. ${ }^{11}$ In the present study, although the complication rate among patients of advanced age was high, disease severity was also high in these patients.

The time interval between event occurrence and rt-PA administration was the same in this study as that in the study by Bergman et al carried out in a similar sized department of internal medicine subunit. ${ }^{12}$ However, in their study, eight more patients were treated than in this study in the same time period. Further, the mean length of hospital stay in their study was the same as that for the control group in this study. Two of their patients died during hospitalization as a result

Table 3 Vital and laboratory parameters

\begin{tabular}{|c|c|c|c|}
\hline Vital and laboratory parameters & Study group & Control group & $P$ value \\
\hline Systolic blood pressure $(\mathrm{mmHg})$ & $167.67 \pm 34.31$ & $143.88 \pm 30.80$ & 0.23 \\
\hline Diastolic blood pressure $(\mathrm{mmHg})$ & $82.5 \pm 13.19$ & $77.29 \pm 18.73$ & 0.61 \\
\hline Heart rate (beats per minute) & $74.5 \pm 18.17$ & $79.07 \pm 14.95$ & 0.78 \\
\hline \multicolumn{4}{|l|}{ Heart rhythm } \\
\hline - Sinus rhythm & $2(33.33 \%)$ & I3 (76.48\%) & 0.57 \\
\hline - Atrial fibrillation & $3(50 \%)$ & $2(11.76 \%)$ & 0.051 \\
\hline - Intermittent atrial fibrillation & I (16.67\%) & $2(11.76 \%)$ & 0.76 \\
\hline \multicolumn{4}{|l|}{ Hematocrit } \\
\hline - Men, normal range $40 \%-51 \%$ & $41.18 \% \pm 5.62 \%$ & $42.13 \% \pm 3.45 \%$ & \\
\hline - Women, normal range $34 \%-45 \%$ & $36.4 \% \pm 8.06 \%$ & $38.66 \% \pm 8.36 \%$ & 0.86 \\
\hline \multicolumn{4}{|l|}{ Blood clotting } \\
\hline - Quick (normal range $70 \%-100 \%$ ) & $73.95 \% \pm 28.19 \%$ & $93.59 \% \pm 12.10 \%$ & 0.052 \\
\hline - INR (range 2-4.5) & $1.11 \pm 0.16$ & $1.59 \pm 2.44$ & 0.12 \\
\hline Blood glucose (mg/dL) & $145 \pm 67.89$ & $|4| .4 \mid \pm 70.87$ & 0.97 \\
\hline \multicolumn{4}{|l|}{ Blood lipids } \\
\hline - Average total cholesterol level (normal $<200$ mg/dL) & $173.5 \pm 52.57$ & $190.5 \pm 92.53$ & 0.72 \\
\hline - Average HDL cholesterol level (normal > 55 mg/dL) & $41.75 \pm 19.92$ & $46.5 \pm 11.80$ & 0.72 \\
\hline - Average LDL cholesterol level (normal $<150$ mg/dL) & $116.25 \pm 39.15$ & $106.14 \pm 24.20$ & 0.38 \\
\hline - Mean triglyceride level (normal < I50 mg/dL) & $74.25 \pm 20.45$ & $139.64 \pm 1 \mid 4.76$ & 0.10 \\
\hline \multicolumn{4}{|l|}{ Kidney function parameters } \\
\hline - Average creatinine level (normal range $0.6-1.2 \mathrm{mg} / \mathrm{dL}$ ) & $1.17 \pm 0.08$ & $1.19 \pm 0.44$ & 0.29 \\
\hline - Glomerular filtration (normal range $80-120 \mathrm{~mL} / \mathrm{min} / 1.73 \mathrm{~m}^{2}$ ) & $59.08 \pm 6.99$ & $63.07 \pm 18.66$ & 0.47 \\
\hline
\end{tabular}

Abbreviations: HDL, high-density lipoprotein; LDL, low-density lipoprotein; INR, International Normalized Ratio. 
Table 4 Antiplatelet and anticoagulant treatment

\begin{tabular}{|c|c|c|c|c|c|}
\hline Antiplatelet and anticoagulant medical treatment & Study group & $\%$ & Control group & $\%$ & $P$ value \\
\hline Aspirin pretreatment medication & 5 & 83.33 & 14 & 82.35 & 0.96 \\
\hline Low-dose heparin & 3 & 50.00 & 8 & 47.06 & 0.90 \\
\hline Complete heparinization & 1 & 16.67 & 4 & 23.53 & 0.73 \\
\hline \multicolumn{6}{|l|}{ K antagonist (phenprocoumon) } \\
\hline After alteplase & 1 & 16.67 & 4 & 23.53 & 0.73 \\
\hline Before alteplase & 0 & 0.00 & I & 5.88 & 0.54 \\
\hline Dipyridamole and acetylsalicylic acid (Aggrenox $\left.{ }^{\circledR}\right)$ & I & 16.67 & 2 & 11.76 & 0.76 \\
\hline Clopidogrel (Plavix ${ }^{\circledR}$ ) & 0 & 0.00 & I & 5.88 & 0.54 \\
\hline Statin & 2 & 33.33 & 9 & 52.94 & 0.41 \\
\hline
\end{tabular}

of severe intracerebral hemorrhage, and three patients had minor hemorrhages detected on brain computed tomography. The complication rate appears similar in both studies.

Several factors have been reported to explain the underuse of thrombolytic therapy for ischemic stroke, ie, the short therapeutic window, insufficient public awareness of stroke symptoms, the limited number of centers able to perform thrombolysis on a 24-hour basis, and the high risk of hemorrhagic complications. ${ }^{13}$

In the present study, four patients had intracerebral hemorrhage. Intracerebral hemorrhage mostly occurs in the core of the infarcted area, suggesting that ischemic events play an important role in its occurrence. ${ }^{14} \mathrm{~A}$ hemorrhagic transformation can occur spontaneously and sometimes during the early hours of a cerebral infarction. For obvious reasons, the hemorrhagic risk increases with administration of heparin or a thrombolytic agent. Low-dose heparin or complete heparinization is administered only after thrombolytic therapy in this hospital.

Many factors contribute to rt-PA-related intracranial hemorrhage, including age, hypertension, diabetes mellitus, or cerebral amyloid angiopathy, extent of early ischemic signs shown on brain computed tomography or volume of cerebral ischemic lesions on diffusion-weighted magnetic

Table 5 NIHSS results and results of the modified Rankin Scale and the Barthel index

\begin{tabular}{lrll}
\hline Scores & \multicolumn{1}{l}{$\begin{array}{l}\text { Study } \\
\text { group }\end{array}$} & $\begin{array}{l}\text { Control } \\
\text { group }\end{array}$ & P value \\
\hline NIHSS & $22.33 \pm 9.54$ & $14.06 \pm 10.59$ & 0.14 \\
Rankin Scale & & & \\
- Before the event & $0.33 \pm 0.82$ & $0.41 \pm 1.23$ & 1.0 \\
- 24 hours after admission & $4.67 \pm 0.82$ & $3.71 \pm 1.45$ & 0.14 \\
- Before discharge & $5 \pm 1.27$ & $3 \pm 2$ & 0.04 \\
Barthel index & & & \\
- Before the event & $96.67 \pm 8.17$ & \multicolumn{1}{l}{100} & 0.56 \\
- 24 hours after admission & $10.83 \pm 15.30$ & $27.94 \pm 28.07$ & 0.26 \\
- Before discharge & $40 \pm 26.46$ & $57 \pm 36.93$ & 0.43 \\
\hline
\end{tabular}

Abbreviation: NIHSS, National Institutes of Health Stroke Survey. resonance imaging, and the presence of leukoaraiosis. ${ }^{15-18}$ Many patients in both groups in this study had high blood pressure and diabetes, and blood pressure increased after thrombolysis in many patients.

A long door-to-needle time has also been shown to be associated with higher rates of intracranial hemorrhage. ${ }^{19}$ However, most studies have not identified time to initiation of thrombolytic treatment as an independent risk factor for intracranial hemorrhage via multivariate analysis, and a pooled analysis of studies failed to show an independent association between timing of rt-PA administration and risk of cerebral hemorrhage. ${ }^{19}$ The time intervals between occurrence of the event and admission and that between admission and the start of lysis were not too long in either group in this study.

The initial trials on rt-PA therapy have provided evidence that higher doses of lytic agents are associated with higher rates of intracranial hemorrhage. ${ }^{20}$ Therefore, in this study, the dose was limited to $0.9 \mathrm{mg} / \mathrm{kg}$ up to a maximum of $90 \mathrm{mg}$. Thus, only the recommended dose of alteplase was used for patients in this study.

Many authors have shown an association between the baseline stroke severity and hemorrhagic risk after thrombolysis. ${ }^{21,22}$ The NINDS (National Institute of Neurological Disorders and Stroke) study showed that patients with a baseline NIHSS score of 20 were 11 times more likely to experience intracranial hemorrhage than those with a score of 5.25. The Multicentre rt-PA Acute Stroke Survey also showed that the NIHSS score was an independent marker of intracranial hemorrhage, with an odds ratio

Table 6 Data on rehabilitation, treatment on discharge, and counseling

\begin{tabular}{llllll}
\hline Therapy & $\begin{array}{l}\text { Study } \\
\text { group }\end{array}$ & $\%$ & $\begin{array}{l}\text { Control } \\
\text { group }\end{array}$ & $\%$ & P value \\
\hline Physical & 2 & 33.33 & 10 & 58.82 & 0.28 \\
Speech & 4 & 66.67 & $1 \mathrm{I}$ & 64.71 & 0.93 \\
Mobilization & 4 & 66.67 & 13 & 76.47 & 0.64 \\
Rehabilitation & 3 & 50.00 & 6 & 35.29 & 0.53 \\
\hline
\end{tabular}


Table 7 Time of stroke symptom onset and time lines

\begin{tabular}{|c|c|c|c|}
\hline Time (minutes) & $\begin{array}{l}\text { Study } \\
\text { group }\end{array}$ & $\begin{array}{l}\text { Control } \\
\text { group }\end{array}$ & $P$ value \\
\hline $\begin{array}{l}\text { Between event occurrence } \\
\text { and recording at the hospital }\end{array}$ & $110 \pm 45.17$ & $98.57 \pm 38$ & 0.66 \\
\hline $\begin{array}{l}\text { Between admission and cranial } \\
\text { computed tomography }\end{array}$ & $30 \pm 14$ & $30 \pm 16$ & 1.0 \\
\hline $\begin{array}{l}\text { Between admission and the } \\
\text { initiation of thrombolysis }\end{array}$ & $49 \pm 37.07$ & $35.29 \pm 11.79$ & 0.86 \\
\hline $\begin{array}{l}\text { Persistence of symptoms } \\
\text { longer than } 24 \text { hours }\end{array}$ & $6(100 \%)$ & 12 (70.59\%) & 0.13 \\
\hline $\begin{array}{l}\text { Duration of symptoms until } \\
60 \text { minutes }\end{array}$ & 0 & 5 (29.4I\%) & 0.13 \\
\hline
\end{tabular}

of 1.38 for a one-point increase in NIHSS score. ${ }^{22}$ On the basis of these results, in some countries, an NIHSS score of 25 is considered a contraindication to alteplase treatment. In contrast with the NINDS study, Sylaja et al did not find a significant association between the severity of neurological deficit at baseline and an increased risk of intracranial hemorrhage. ${ }^{23}$ Moreover, ECASS ${ }^{19}$ (European Cooperative Acute Stroke Study) I showed that severity of neurological deficit at admission was a risk factor for hemorrhagic transformation and not parenchymal hematoma. In this study, the mean NIHSS score was 22.33 in the study group, which experienced complications caused by alteplase treatment, and 14.06 in the control group. Thus, stroke severity and high NIHSS values can be suspected to be associated with high rates of complications due to alteplase treatment.

It is well known that patients with hyperglycemia have poorer outcomes than those with normal blood glucose levels at presentation. ${ }^{24}$ Studies, including those on humans, indicate that hyperglycemia predicts higher stroke mortality independently of stroke severity, stroke type, or age. These data suggest that hyperglycemia contributes directly to poor outcomes by exacerbating acute brain injury. ${ }^{25-27}$ Alternatively, it has been proposed that hyperglycemia is simply a bystander phenomenon, a catecholamine-based stress response to a severe stroke, which may not play a direct causative role in the poor prognosis observed for these patients. ${ }^{28-30}$ In the present study, the blood sugar level was high $(>200 \mathrm{mg} / \mathrm{dL})$ in two patients in each group, and it further increased in three patients in the control group at admission. Five patients each in the two groups had diabetes mellitus. Several studies have shown the influence of baseline hyperglycemia on the risk of intracerebral hemorrhage after thrombolysis. ${ }^{31-33}$ In a study published in 1999, patients with a blood sugar level $\geq 200 \mathrm{mg} / \mathrm{dL}$ on admission showed a symptomatic hematoma rate of $25 \%$ after treatment with rt-PA. ${ }^{32}$

A previous study showed that the effect of statin therapy on stroke outcome did not play a role in stroke recovery or consequent long-term prognosis. ${ }^{34}$ In this study, all surviving patients were treated with statins for secondary prevention of recurrent strokes.

Antiplatelet agents yield a small but significant benefit in the long-term functional outcome and survival of stroke patients, and they have become the standard treatment for acute ischemic stroke..$^{35}$ Anticoagulants are often used as an alternative, despite evidence that they are ineffective in providing long-term benefits, and they offer no net advantages over antiplatelet agents in acute ischemic stroke..$^{35}$ In a previous subgroup analysis, the combination of low-dose unfractionated heparin and aspirin showed better results than

Table 8 Comorbidities

\begin{tabular}{lllll}
\hline Comorbidities & Study group & Control group & $\begin{array}{l}\text { \% Study/control } \\
\text { group }\end{array}$ \\
\hline Heart and circulatory & & & $42.31 / 34.88$ & P value \\
Lung & $\mathrm{II}$ & 15 & $23.08 / 9.30$ & 0.54 \\
Renal & 6 & 4 & $0.00 / 4.65$ & 0.12 \\
Gastrointestinal diseases & 0 & 2 & $3.85 / 13.95$ & 0.26 \\
Bone diseases & $\mathrm{I}$ & 6 & $3.85 / 9.30$ & 0.18 \\
Thyroid disorders & $\mathrm{I}$ & 4 & $0.00 / 6.98$ & 0.40 \\
Ear, nose, throat diseases & 0 & 3 & $2.69 / 0.00$ & 0.17 \\
Cancer & 2 & 0 & $0.00 / 4.65$ & 0.06 \\
Gynecologic & 0 & 2 & $0.00 / 2.33$ & 0.26 \\
Urologic & 0 & $\mathrm{I}$ & $3.85 / 2.33$ & 0.43 \\
Accidents & $\mathrm{I}$ & $\mathrm{I}$ & $11.54 / 2.33$ & 0.72 \\
Neurologic & 3 & $\mathrm{I}$ & $0.00 / 6.98$ & 0.11 \\
Psychiatric & 0 & 3 & $0.00 / 2.33$ & 0.17 \\
Ophthalmologic & 0 & $\mathrm{I}$ & $3.85 / 0.00$ & 0.43 \\
Total number of diagnoses & $\mathrm{I}$ & 0 & $100 / 100$ & 0.20 \\
(n=69) & 26 & 43 & & 0.11 \\
\hline
\end{tabular}


aspirin alone. ${ }^{35}$ Most patients in both groups in this study had received aspirin before alteplase treatment. Aspirin or clopidogrel (Plavix ${ }^{\circledR}$, sanofi aventis, Paris, France), in addition to dipyridamole and acetylsalicylic acid (Aggrenox ${ }^{\circledR}$; Boehringer Ingelheim, Ingelheim, Germany), was also prescribed at discharge for secondary stroke prevention.

\section{Conclusion}

Although alteplase remained as the only therapy for the treatment of acute ischemic stroke, intracranial hemorrhage is common. However, the complication rate was statistically low during the treatment of acute ischemic stroke with alteplase in this study. The stroke incidence and number of patients treated with alteplase has not increased in the last few years. The results of the present study showed that stroke severity and high NIHSS values may be associated with high complication rates after alteplase treatment. The predictive value of these factors should be explored in future studies.

\section{Disclosure}

The author reports no conflicts of interest in this work.

\section{References}

1. Amiri H, Hacke W, Bösel J. Thrombolytic treatment of acute stroke. Internist (Berl). 2011;52:1310-1316. German.

2. Micieli G, Marcheselli S, Tosi PA. Safety and efficacy of alteplase in the treatment of acute ischemic stroke. Vasc Health Risk Manag. 2009;5:397-409.

3. National Institute of Neurological Disorders and Stroke Study Group. Tissue plasminogen activator for acute ischemic stroke. N Engl J Med. 1995;333:1581-1587.

4. Kaste M, Thomassen L, Grond M, et al. Thrombolysis for acute ischemic stroke: a consensus statement of the 3rd Karolinska Stroke Update, October 30-31, 2000. Stroke. 2001;32:2717-2718.

5. Adams HP Jr, Adams RJ, Brott T, et al. Guidelines for the early management of patients with ischemic stroke: a scientific statement from the Stroke Council of the American Stroke Association. Stroke. 2003;34:1056-1083.

6. Olsen TS, Langhorne P, Diener HC, et al; European Stroke Initiative Executive Committee. EUSI Writing Committee, European Stroke Initiative Recommendations for Stroke Management - update 2003. Cerebrovasc Dis. 2003;16:311-337.

7. Appelros P, Stegmayr B, Terént A. Sex differences in stroke epidemiology: a systematic review. Stroke. 2009;40:1082-1090.

8. Redon J, Olsen MH, Cooper RS, et al. Stroke mortality and trends from 1990 to 2006 in 39 countries from Europe and Central Asia: implications for control of high blood pressure. Eur Heart J. 2011;32:1424-1431.

9. Stegmayr B, Eriksson M, Asplund K. Declining mortality from subarachnoid hemorrhage: changes in incidence and case fatality from 1985 through 2000. Stroke. 2004;35:2059-2063.

10. Kazlauskas H, Raškauskienė N, Radžiuvienė R, Janušonis V. Stroke mortality trends in the population of Klaipeda from 1994 to 2008. Medicina (Kaunas). 2011;47:512-519.

11. Asdaghi N, Butcher KS, Hill MD. Risks and benefits of thrombolysis in the elderly. Int J Stroke. 2012;7:142-149.

12. Bergman M, Ori Y, Blumberger N, Salman H. An alternative facility for a stroke unit in a community hospital. Eur J Intern Med. 2011;22:505-508.
13. Reeves MJ, Arora S, Broderick JP, et al. Acute stroke care in the US: results from the 4 pilot prototypes of the Paul Coverdell National Acute Stroke Registry. Stroke. 2005;36:1232-1240.

14. Savitz SI, Lew R, Bluhmki E, Hacke W, Fisher M. Shift analysis versus dichotomization of the modified Rankin Scale outcome scores in the NINDS and ECASS II trials. Stroke. 2007;38:3205-3212.

15. Hacke W, Kaste M, Fieschi C, et al. Intravenous thrombolysis with recombinant tissue plasminogen activator for acute hemispheric stroke. JAMA. 1995;274:1017-1025.

16. Ribo M, Montaner J, Molina CA, et al. Admission fibrinolytic profile is associated with symptomatic hemorrhagic transformation in stroke patients treated with tissue plasminogen activator. Stroke. 2004; 35:2123-2127.

17. Derex L, Hermier M, Adeleine P, et al. Clinical and imaging predictors of intracerebral hemorrhage in stroke patients treated with intravenous tissue plasminogen activator. J Neurol Neurosurg Psychiatry. 2005;76: $70-75$.

18. Larrue V, von Kummer R, del Zoppo G, Bluhmki E. Hemorrhagic transformation in acute ischemic stroke. Potential contributing factors in the European Cooperative Acute Stroke Study. Stroke. 1997; 28:957-960.

19. Fiorelli M, Bastianello S, von Kummer R, et al. Hemorrhagic transformation within 36 hours of a cerebral infarct: relationships with early clinical deterioration and 3-month outcome in the European Cooperative Acute Stroke Study I (ECASS I) cohort. Stroke. 1999;30: 2280-2284.

20. Cocho D, Borrell M, Marti-Fabregas J, et al. Pretreatment hemostatic markers of symptomatic intracerebral hemorrhage in patients treated with tissue plasminogen activator. Stroke. 2006;37: 996-999.

21. The National Institute of Neurological Disorders and Stroke rt-PA Stroke Study Group. Tissue plasminogen activator for acute ischemic stroke. N Engl J Med. 1995;333:1581-1587.

22. Heuschmann PU, Kolominsky-Rabas PL, Roether J, et al. Predictors of in-hospital mortality in patients with acute ischemic stroke treated with thrombolytic therapy. JAMA. 2004;292:1831-1838.

23. Sylaja PN, Cote R, Buchan AM, Hill MD; on behalf of Canadian Alteplase for Stroke Effectiveness Study (CASES) Investigators. Thrombolysis in patients older than 80 years with acute ischaemic stroke: Canadian Alteplase for Stroke Effectiveness Study. J Neurol Neurosurg Psychiatry. 2006;77:826-829.

24. Wardlaw JM, Dorman PJ, Caldelise L, Signorini DF. The influence of baseline prognostic variables on outcome after thrombolysis. MASTItaly Collaborative group. J Neurol. 1999;246:1059-1062.

25. Capes SE, Hunt D, Malmberg K, Pathak P, Gerstein HC. Stress hyperglycemia and prognosis of stroke in nondiabetic and diabetic patients: a systematic overview. Stroke. 2001;32:2426-2432.

26. Weir CJ, Murray GD, Dyker AG, Lees KR. Is hyperglycaemia an independent predictor of poor outcome after acute stroke? Results of a long-term follow up study. BMJ. 1997;314:1303-1306.

27. Jorgensen H, Nakayama H, Raaschou HO, Olsen TS. Stroke in patients with diabetes. The Copenhagen Stroke Study. Stroke. 1994;25: 1977-1984.

28. van Kooten F, Hoogerbruge N, Naarding P, Koudstaal PJ. Hyperglycemia in the acute phase of stroke is not caused by stress. Stroke. 1993;24:1129-1132.

29. Murros K, Fogelholm R, Kettunen S, Vuorela AL, Valve J. Blood glucose, glycosylated haemoglobin, and outcome of ischemic brain infarction. J Neurol Sci. 1992;111:59-64.

30. Murros K, Fogelholmd R. Diabetes and stress hyperglycaemia in stroke. J Neurol Neurosurg Psychiatry. 1993;56:428.

31. Levy D, Brott T, Haley EC Jr, et al. Factors related to intracranial hematoma formation in patients receiving tissue-type plasminogen activator for acute ischemic stroke. Stroke. 1994;25:291-297.

32. Demchuk AM, Morgenstern LB, Krieger DW, et al. Serum glucose level and diabetes predict tissue plasminogen activator-related intracerebral hemorrhage in acute ischemic stroke. Stroke. 1999;30:34-39. 
33. Woo E, Ma JT, Robinson JD, Yu YL. Hyperglycemia is a stress response in acute stroke. Stroke. 1988;19:1359-1364.

34. Zare M, Saadatinia M, Mousavi SA, Keyhanian K, Davoudi V, Khanmohammadi E. The effect of statin therapy in stroke outcome: a double blind clinical trial. Int J Prev Med. 2012;3:68-72.
35. Berge E, Sandercock P. Anticoagulants versus antiplatelet agents for acute ischaemic stroke. Cochrane Database Syst Rev. 2002;4:CD003242.

International Journal of General Medicine

\section{Publish your work in this journal}

The International Journal of General Medicine is an international, peer-reviewed open-access journal that focuses on general and internal medicine, pathogenesis, epidemiology, diagnosis, monitoring and treatment protocols. The journal is characterized by the rapid reporting of reviews, original research and clinical studies across all disease areas.
A key focus is the elucidation of disease processes and management protocols resulting in improved outcomes for the patient.The manuscript management system is completely online and includes a very quick and fair peer-review system. Visit http://www.dovepress.com/ testimonials.php to read real quotes from published authors.

Submit your manuscript here: http://www.dovepress.com/international-journal-of-general-medicine-journal 